\title{
Dynamic Interaction through a Reactive Interface in Patients with Dementia, by Means of Cognitive Stimulation
}

\author{
Ana Lilia Laureano-Cruces1,2, Martha Mora-Torres², Lourdes Sánchez-Guerrero1, \\ Javier Ramírez-Rodríguez ${ }^{1}$, Itzel Iraís Montiel-Bernal3 ${ }^{3}$, Eric Benjamín Allier-Pavia ${ }^{4}$ \\ ${ }^{1}$ Departamento de Sistemas, Universidad Autónoma Metropolitana-Azcapotzalco, México City, \\ México \\ ${ }^{2}$ Posgrado en Ciencia e Ingeniería de la Computación, Universidad Nacional Autónoma de México, México City, \\ México \\ ${ }^{3}$ Escuela Superior de Cómputo-Instituto Politécnico Nacional, México City, México \\ ${ }^{4}$ Posgrado en Diseño, Línea: Visualización de la Información, Universidad Autónoma Metropolitana-Azcapotzalco, \\ México City, México \\ Email: \{clc,Isg,jararo\}@azc.uam.mx,kabhun@yahoo.com.mx,itzel.montielbernal@gmail.com, \\ dcg.eric.allier@gmail.com
}

Received 18 September 2015; accepted 14 November 2015; published 17 November 2015

Copyright (C) 2015 by authors and Scientific Research Publishing Inc.

This work is licensed under the Creative Commons Attribution International License (CC BY). http://creativecommons.org/licenses/by/4.0/

(c) (i) Open Access

\section{Abstract}

Dementia is a syndrome of chronic and progressive nature, characterized by the deterioration of cognitive functions and behavior, which causes a disability and dependence on others. Alzheimer's Disease is a type of dementia that affects cognitive functioning, behavior, and overall functionality of those who suffer from the irremediably progressive form, as it is a neurodegenerative disease. For this reason, development of a reactive interface is proposed to be inserted in a cognitive stimulation program. This program offers a series of exercises of mental functions, in order to delay or slow down the progress of this illness. The reactive interface allows access to these exercises and incorporates a user profile that predicts the possible emotions that may be experienced during the work sessions. In order to accomplish this, a cognitive structure of emotions is developed to be included in the reactive profile. This will allow enhancement of the interaction between the system and the patient. The user's emotional state may interfere, considering within the design stage the phenomenon of altered consciousness during this degenerative process. The consciousness represents the interface of human beings with our environment. This proposal allows us to obtain information related to the user's emotional state during the performance of specific cognitive tasks, permitting us to optimize the proposed stimulation activities.

How to cite this paper: Laureano-Cruces, A.L., Mora-Torres, M., Sánchez-Guerrero, L., Ramírez-Rodríguez, J., MontielBernal, I.I. and Allier-Pavia, E.B. (2015) Dynamic Interaction through a Reactive Interface in Patients with Dementia, by Means of Cognitive Stimulation. E-Health Telecommunication Systems and Networks, 4, 57-67.

http://dx.doi.org/10.4236/etsn.2015.44006 


\section{Keywords}

\section{Dementia, Alzheimer, Cognitive Stimulation, Artificial Consciousness, Cognitive Structure of the Emotions}

\section{Introduction}

The brain is without a doubt the most fascinating organ of study, giving rise to a wide variety of forms of approaching its study, comprised under the rubric of neuroscience. On this occasion we solely make reference to two topics in this field: 1) degenerative dementia, more often known as Alzheimer's Disease (AD), and a broad and complex topic termed 2) the consciousness, both of which represent constant questioning in diverse fields such as, medicine, neurology, psychology, philosophy, affective computation and engineering, among others.

The global population has been aging at an accelerated rate since the last century due to advances that have been made in health studies, translating into longer lives. However, this phenomenon has favored an increase in the number of people with non-communicable diseases, including dementia.

Dementia is a syndrome of chronic and progressive nature, characterized by the deterioration of cognitive functions and behavior, which causes a disability and dependence on others

It was estimated that in 201035.6 million people worldwide lived with dementia, and it was predicted that this figure would double every 20 years, reaching 65.7 million in 2030 and 115.4 million by 2050 . Annually, the total number of new cases of dementia is nearly 7.7 million, which means one new case every four seconds.

In 2010, the total estimated cost of dementia worldwide was 604 billion dollars per year. In high-income countries, informal health care, that is, services offered directly by relatives who take care of the ill, is estimated for $45 \%$, while it is estimated that $40 \%$ receive formal or specialized health care, which represents the majority of the cost of the illness, and the remaining $15 \%$ is the corresponding estimate of the direct medical cost. In contrast, in low- and middle-income countries, the direct social costs are low because informal health care costs, paid by family members, are predominant. With the next few decades, the demographic changes in these countries can lead to a decrease in immediate availability of family members in these populations who can provide such type of care.

The most pressing key points addressed by the report Dementia: A Public Health Care Priority are:

- People live for many years after the appearance of symptoms of dementia. With proper assistance, many can and should have the opportunity to continue participating and contributing to society, and enjoy a good quality of life;

- Dementia is tiring for caregivers who need adequate support by financial, legal, social and health care systems;

- The countries should include dementia in their public health agendas... This requires coordination and sustained action among the distinct levels, which includes the interested parties on the sector front: international, regional, national and local.

\section{Epidemiological Situation of Dementia in Mexico}

It is commendable that health care advances in Mexico have resulted in data that yield constant overall aging among the population, which shows that the living conditions have improved, along with health care and social protection systems. This has favored an increase in the country's average life expectancy, to 76 years.

Currently, there are more than 10 million adults in the world over 60 years of age; in Mexico, there are more individuals over 60 years old than children under 5 years, and the projections indicate that the phenomenon of demographic aging is irreversible. In considering this data, we must begin to be concerned with improving the quality of life of the elderly.

Worldwide, $31.7 \%$ of the total years lived with a disability are attributed to neuropsychiatric conditions; among the elderly, depression and dementia are the main factors that contribute to this phenomenon. Dementia contributes $11.9 \%$ of the years lived with a disability caused by chronic illnesses, that of greatest proportion, as opposed to those corresponding to: cerebrovascular events (10.1\%), cardiovascular illness $(5.3 \%)$ and cancer $(2.5 \%)$. 
In Mexico epidemiological information now exists on the frequency of dementia and cognitive impairment no dementia (CIND) in the elderly. In accordance with data presented on the prevalence of dementia in Mexico, it is estimated that 800,000 affected individuals exist in the country.

The projection of the number of Mexicans affected by dementia will reach an alarming number of over 3 million by the year 2050, due to which the impact of this illness on the economic, social and health care systems will be severe. The estimated annual incidence is 27 new cases for each thousand individuals aged 65 years or older (Figure 1).

The number of patients who suffer $\mathrm{AD}$ worldwide is on the rise. It was estimated in 2005 that 24.3 million cases of individuals with dementia existed, by 2010 in a new consensus this number rose to 35.6 million, with an increase of 7.7 million per year, and the same group estimated that by the year 2050, over 110 million individuals will be affected by this devastating illness [2]. Among these, approximately $70 \%-75 \%$ suffers $\mathrm{AD}$ and the rest are attributed to other less frequent types of dementia.

Dementia manifests due to progressive deterioration of cognitive functioning, to a degree that negatively impacts the life of affected individuals and their families [3] as the capacity to perform daily activities independently deteriorates, causing disability and dependence [4].

The most common symptoms of $\mathrm{AD}$ correspond to cognitive deterioration; nevertheless, behavioral alterations are generally presented in this group of illnesses, which is a very diverse and complex array of manifestations [5]. In regard to cognitive alterations, diverse studies have been performed that propose a wide array of exercises which attempt to preserve the cognitive abilities as long as possible in patients with dementia, and at the same time help decrease the alterations and improve the quality of life of the patients and their caregivers [2] $[6]$.

The increasingly early onset of non-communicable chronic illnesses translates into more years of life with complications, disability and, in some cases, dependence. On this continuum, dementia is one of the illnesses with greatest impact. Recent studies indicate that in Mexico there is a prevalence of $7.9 \%$, of which the majority occurs in less educated women from rural populations. It is important to mention that the first symptoms of dementia may be identified by non-specialized personnel, permitting early treatment focused on the preservation of functionality and which impact the quality of life.

Based on this evidence, we can say that Mexico is in urgent need of a comprehensive and efficient approach based on the development of a specific plan of action, in order to respond to the needs generated by this illness.

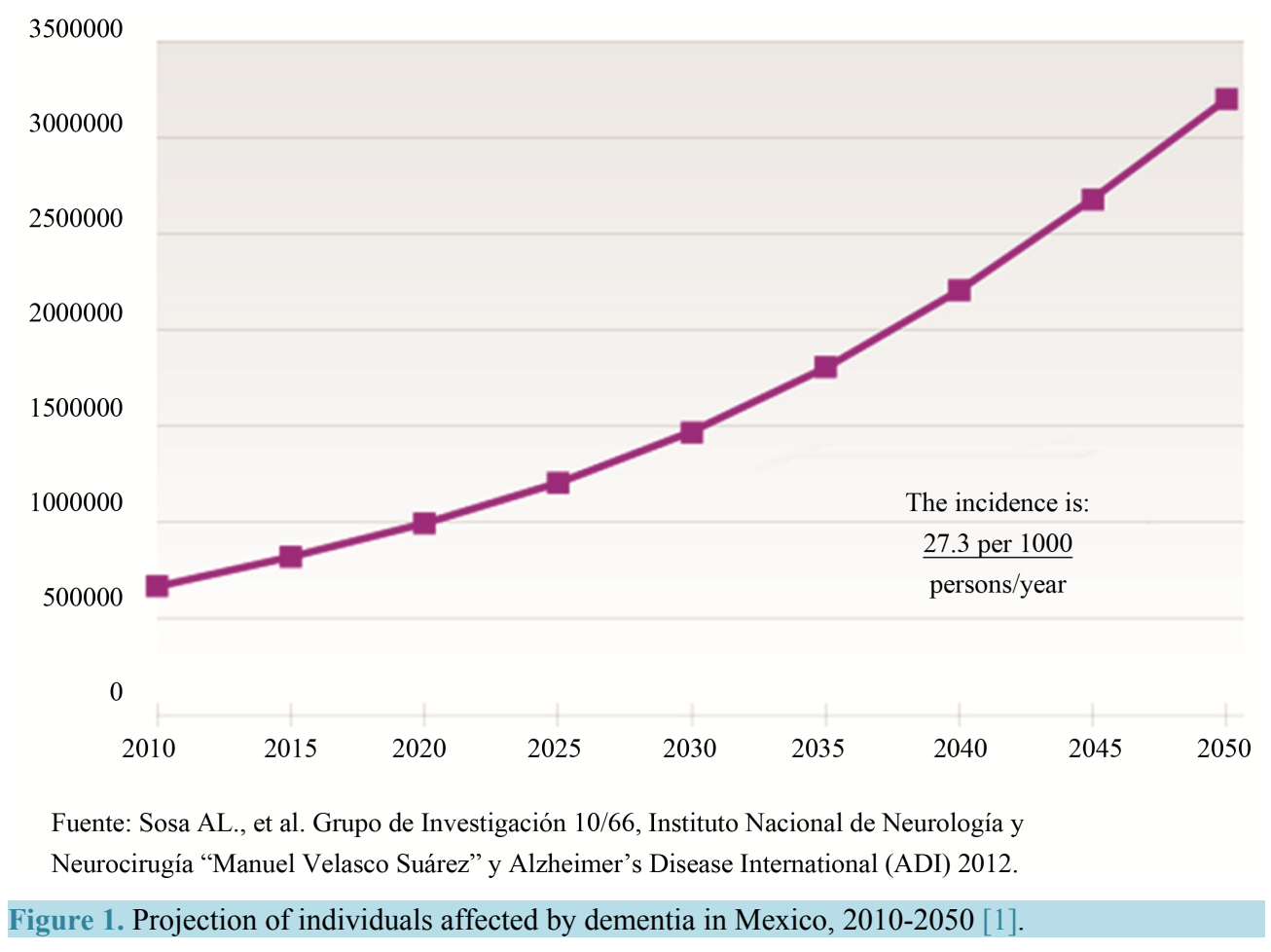


Our work contributes to the development of a reactive interface, to be inserted in a cognitive stimulation program.

The deterioration observed in these patients also involves the deterioration of perception, which affects the experience of the phenomenon of the consciousness. It is stressed that we are not speaking about ethical and moral aspects but to the consciousness that refers to the experience of the phenomenon and its impact on one's life as an organizer and controller of daily activities. For the purpose of simulating this phenomenon beginning with engineering, different models have been proposed that involve the phenomenon of consciousness from an emotional perspective [7] [8].

The consciousness is said to be extensively connected with the phenomenon of perception that according to Potworowski and Ferrari, mentioned in [9], is an internal experience (not including the senses) of coherence or accuracy, a feeling related to the judgment of something appropriate and a strong experience of oneness between the object and the topic. There are at least two sentiments, correct or incorrect, that are connected with concepts and values.

The emotional model we propose to use for this project emphasizes the phenomenon of consciousness, considered as the human interface for interaction with the surroundings. Based on the fact that emotions are one of the internal sources of motivation that guides human behavior, and being that it is one of the implications of perception of the environment, it proves to be a gateway to the phenomenon of the consciousness. It also suggests that the emotions to which we refer are those that are handled cognitively, subsequently leading to the design of a cognitive structure of the emotions (CSE) [10]. This is a design tool that allows us to consider the process of the consciousness through the emotions, connecting them to a determined behavior within a determined context that considers dynamic events.

\section{Alzheimer's Disease (AD)}

Alzheimer's Disease is a progressive neurodegenerative disorder with distinctive clinical and pathological characteristics. It is typically characterized by loss of short-term memory and other mental capacities, as the nerve cells (neurons), die and different zones of the brain atrophy. Currently, more than 800 thousand people suffer dementia in Mexico, a figure that was estimated based on recent studies that have reported a frequency that ranges from $8 \%$ - $9 \%$ of people over 60 years old [11].

Alzheimer's Disease refers to a brain disorder of chronic and progressive nature, in which an alteration of cortical brain functions exists, affecting memory, orientation, denomination, comprehension, calculation, visuospatial functions, praxis and judgment. The deterioration of these cognitive functions is commonly accompanied, and on occasion preceded by, a deterioration of emotional control, social behavior or motivation [12].

In patients with dementia, there is usually no warning of the coming cognitive, behavioral and functional deterioration [13]. This phenomenon has also been called anosognosia and is a condition that significantly complicates the care of these patients and creates major issues for their relatives.

Given all of the complex and progressive forms of dementia, in addition to the condition of growing dependence and loss of control of one's own world and of the surroundings, situations of mistreatment also occur [14].

\section{The Consciousness}

According to Aleksander [15], the consciousness is the capacity to perceive the world and give it meaning through the representations of same in our inner world. For each thing that exists in the external world, there is an internal representation. The individual creates these representations over the years, and they carry experiences that accumulate throughout life. In order to accomplish this, one must be able to place his or her ego in the external world through: 1) the imagination, 2) focusing attention on significant events, 3) planning ahead and 4) feel emotions in regard to what could happen.

\section{Homeostasis and the Emotions}

According to Van Eersel [16], consciousness is the art of remaining in constant instability. This idea is valid for a geranium as well as for a worm; in this case the consciousness refers to the spirit that corresponds to the will to live and to the social capacity to distinguish the interior from the exterior. In other words, it is the art of regulating the chemical measurements of the body. This process is omnipresent and is known as homeostasis. 
When we speak about homeostasis, we are referring to the capacity of a system to self-regulate, in other words, the ability to stabilize, taking into consideration the changes in one's interior in accordance with external changes. The above considering a range of viable thresholds so permit; when stability is attained, this implies death. I this manner, we can say that homeostasis implies life, and this reflection applies for bacteria as well as for a human being. In the case of humans, this translates into living, feeling good and being happy. This reflection leads us to infer that sensations imply emotions.

\section{The Phenomenon of Cartography or Description}

Human beings are conscious because they know and think. Among their mental processes is the creation of cartographies, which allows them to integrate descriptions. This process is carried out continuously by our brain and is developed based on tiny sensations perceived by the body, in this manner generating: 1) an internal model of the self, 2) of the self in the world and thus 3) a model of the world. This development is also valid for a fly, a snail and a bacteria.

In humans, this process allows us to go beyond any other known living being. This is due to our high capacity to generate descriptions and integrate them as one. In addition, the human recognizes these descriptions internally as its own, giving rise to an occurrence called I am.

\section{Cognitive Structure of the Emotions (CSE)}

According to Rosalind Picard [17], if we attempt to develop systems capable of simulating intelligent behaviors that are therefore adapted and related in a natural manner with humans, these shall have the following abilities: 1) recognize, 2) express and 3) have emotions. This is, in essence, to have what we have come to know as emotional intelligence [18].

The OCC theory [19] specifies a psychological structure of emotions according to personal and interpersonal descriptions of diverse situations. In addition, it constitutes the base to model an affective structure that may be formalized computationally. In other words, it is possible to create an affective-motivational cognitive model that may be utilized in artificial intelligence systems and linked to the system of reasoning in order to enhance the performance of the interaction of any software development, which in the case study is a reactive interface with affective aspects [10].

Ortony, Clore and Collins [19] propose a general structure in which it is specified that three major categories of emotions exist, if we focus on each of the three highlighted aspects of the world: 1) events and their consequences, 2) agents and their actions and 3) pure and simple objects.

For this, it establishes assessment criteria: 1) targets for evaluating events, 2) standards for evaluating the action of the agents, and 3) attitudes for evaluating the objects.

The three major categories of emotions are: 1) emotions based on events: these elaborate consequences of desirable or undesirable events in relation to the targets, 2) emotions of attribution: these attribute responsibility to agents for their actions according to standards, and 3) emotions of attraction: these are based on attitudes related to objects. Based on these definitions, the following section develops a CSE considering the possible emotions of the user during a therapy session containing exercises, focusing on the events presented during this cognitive exercise and their relation to the axioms implied by the consciousness according to Aleksander [15].

The OCC theory proposes three local variables in accordance with the three classes of emotions, which are: 1) desirability, 2) attribution and 3) attraction, and four global variables that could affect any of the 3 categories of emotions: 1) the unexpected, 2) proximity, 3) sense of reality and 4) excitation, for the purpose of being able to evaluate the surroundings and be able to nurture the distinct emotions.

\section{Unification of the Models}

According to Aleksander's five axioms, a relationship is established with the symptoms presented by Alzheimer patients.

\subsection{Axiom 1. I Feel I Belong, but Part of Me Is Separated from the Outside World}

- Results in a loss of identity (this happens in very advanced stages of the illness, first they stop recognizing the world around them: 1) as it is, and 2) who is in it. This causes them to feel frightened. 
- They stop feeling part of something, of society or, for example, of the family (they identify the family in the beginning and in the moderate stage of the illness, but cease to recognize them in advanced stages), they do not know what their role is and as such, what it implies to perform within their surroundings. They no longer recognize the world or the relationship they have with it.

\subsection{Axiom 2. I Feel That My Perception of the World Is Mixed with Feelings of Past Experiences}

- Upon losing the memory, one's perception of the world is affected, because memories are gone or may be distorted, disordered or incomplete.

- Without memories of past experiences, one loses fears around dangerous actions.

- However, the last memory to be lost is the affective memory. Patients may not remember their children as they are, but they are located in their affective memory: they are part of an emotionally meaningful and close group, even when they are mistakenly identified as brothers or parents. They generally feel safe and content with them, especially if they had a good relationship was good in the past

\subsection{Axiom 3. My Experience of the World Is Selective and Has a Purpose}

- Without experiences, they do not know what to base themselves on in order to determine the purpose of their actions.

- They do not know which decisions to make.

- They do not have an alarm system that serves as an anchor or security net to avoid risks. For this reason, they do not know how to act when they are in danger; in fact, they may not even know they are in danger.

- They gradually forget their purposes in life and slowly lose the ability to decide, plan and execute.

- They cease to recognize some but not all signs of danger.

\subsection{Axiom 4. I Am Always Thinking Ahead, Trying to Decide What I Will Do Next}

- The prospective memory is altered, which is related to what we were going to do. Also, the symptom of apathy may be experienced (lack of motivation), abulia (lack of will) and problems with planning and execution (executive functions).

- Objectives are lost, and there is no purpose for deciding which actions to carry out.

\subsection{Axiom 5. I Have Feelings, Emotions and Moods That Determine What I Will Do}

- They are given less notice regarding their emotions and the effect of same.

- They inadvertently react to their emotions with no control over them.

- They frequently feel frustration, impotence, anger and anguish, among other emotions, but are unable to forewarn and regulate them at will.

- They may have disastrous reactions to threatening events.

- New feelings arise, negative feelings as a result of not being able to remember.

- The lack of memory makes it impossible to use previously acquired feelings and emotions.

\section{Analysis and Design of the Interface}

Based on the previous reflections, the CES is developed which implies the possible emotions presented upon: 1) the inability to complete, 2) partially complete, or 3) complete; within the context of the performance of the exercise of the therapy and the type of response the system must give the user (see Figures 2-4).

Based on the mental model (Figure 2 and Figure 3 ) that represents the behavior of the reactive interface, this of course incorporates the dynamic events within its reactivity that will be interpreted through the CES (Figure 4) as well as the response strategies that include the inferred emotions.

In this case the primary mental model implies completing a therapy; the final pursued objective is for the user to be able to: perform activities, have a happy family and feel self-fulfillment.

In the case study we have decided that the variables which allow evaluation of the different events from the environment that we will take into consideration and that will be evaluated from the point of view of the user are: 1) sense of reality and 2) excitation. 


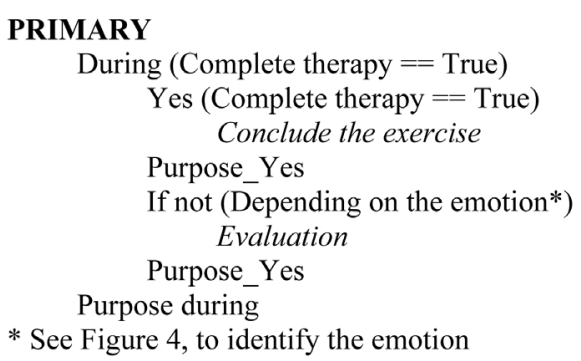

Figure 2. Mental model of the behavior of the reactive interface.

\section{Evaluation \\ During (Resolve exercise $==$ True $)$}

Give hint or

Encourage through a message or

\section{Change exercise}

Purpose during

Figure 3. Secondary mental model of the behavior of the reactive interface.

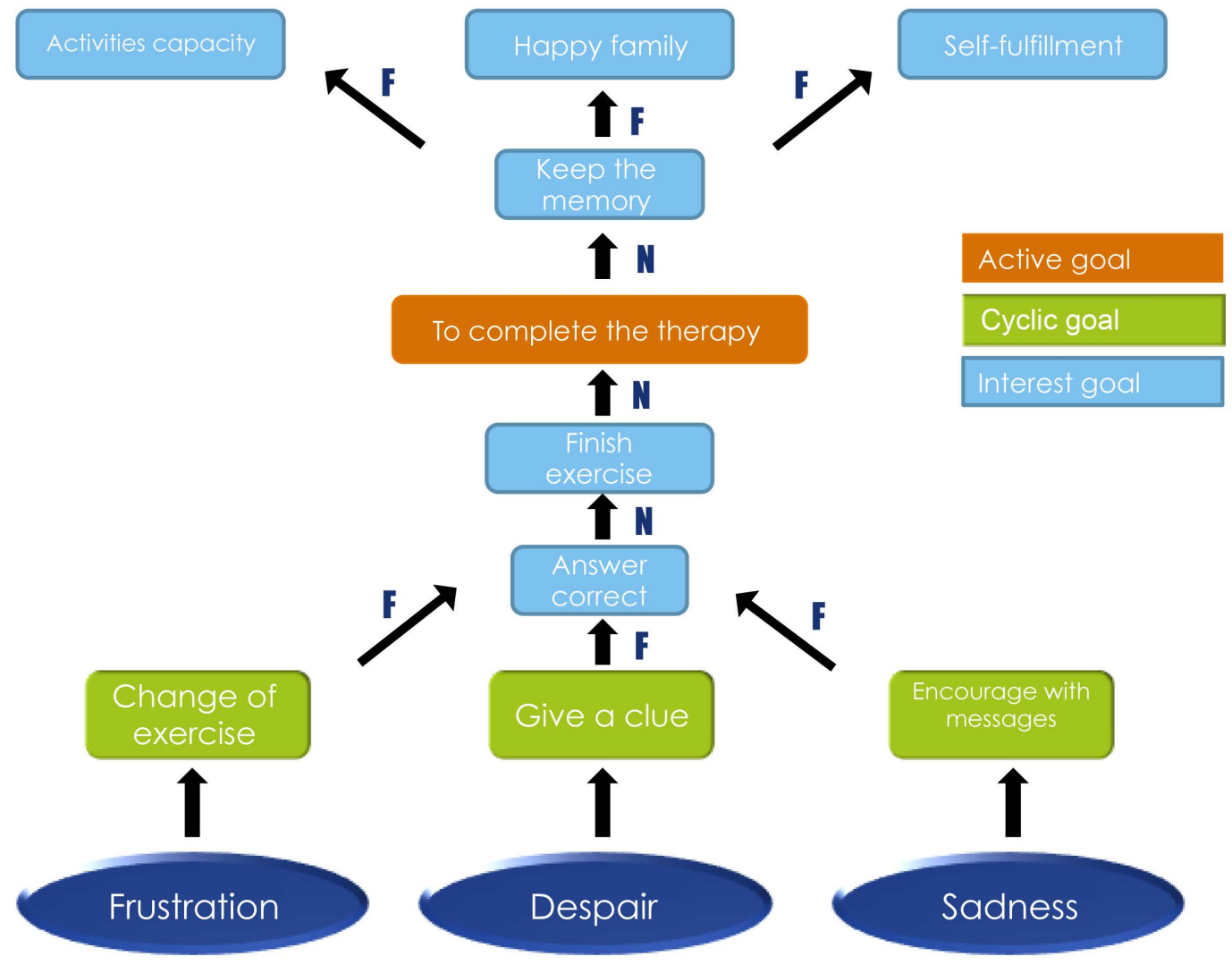

Figure 4. Cognitive structure of emotions of the behavior in completing the therapy.

The Emotions that operate on one axis with the two extremes are:

- Frustration-Triumph;

- Despair-Tranquility;

- Sadness-Happiness.

Depending on these, the necessary answers will be given in order for the user to complete the therapy.

Given that patients are in a relatively advanced stage of the illness, the type of exercises is related with songs 
and refrains from their epoch and gives them a greater or lesser sense of reality, due to which if they are unable to resolve the exercises, we know that these no longer form part of their consciousness and we infer the emotion of sadness On the other hand, despair and frustration imply excitation, so the more errors they commit the more excitation they will feel. The form of evaluating them will be by the number of times they have to be provided with feedback, of which we find positive and negative excitation [19].

\section{Specific Emotions in Three Exercises That Imply the Axioms of the Phenomenon of the Consciousness}

In this section we describe the use of the interface utilizing three specific exercises from the cognitive stimulation program, with the possible emotions that may be presented based on the different Axioms. It is important to mention that not all of the axioms will be involved, or where appropriate they will result in the same emotions in different contexts. This will give us an idea for the distinct interventions by the reactive interface.

EXERCISE 1

Stimulated area: Memory and Attention;

Level of difficulty: Low;

Periodicity: Daily;

Instructions: Observe and memorize the sequence.

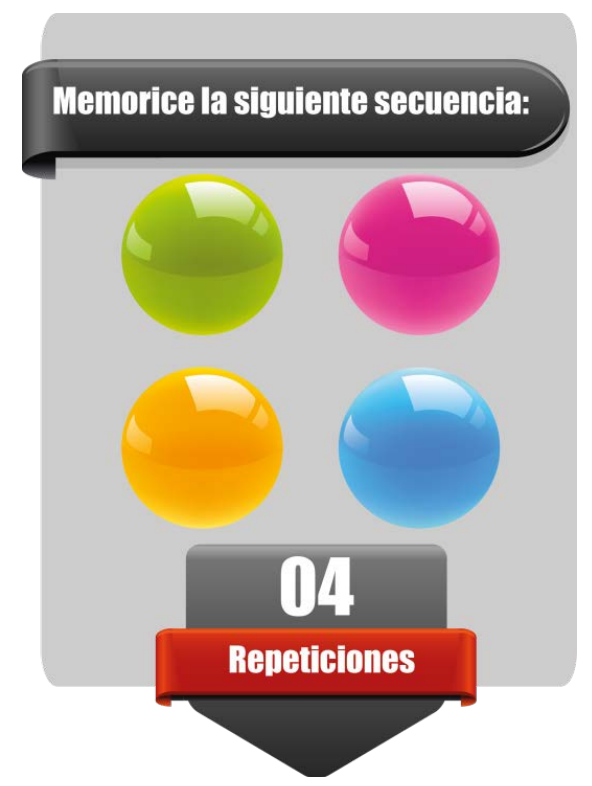

Axiom(s): Axiom 1. I feel I belong, but part of me is separated from the outside world.

Possible emotions and reaction of the system:

Despair

Actions:

Present the sequence again;

Present an easier exercise.

Frustration

Actions:

Give the correct sequence;

Change the activity.

EXERCISE 2

Stimulated area: Orientation and Memory;

Level of difficulty: Medium-Low;

Periodicity: Daily;

Instructions: Read the statement and select the option that completes the phrase. 


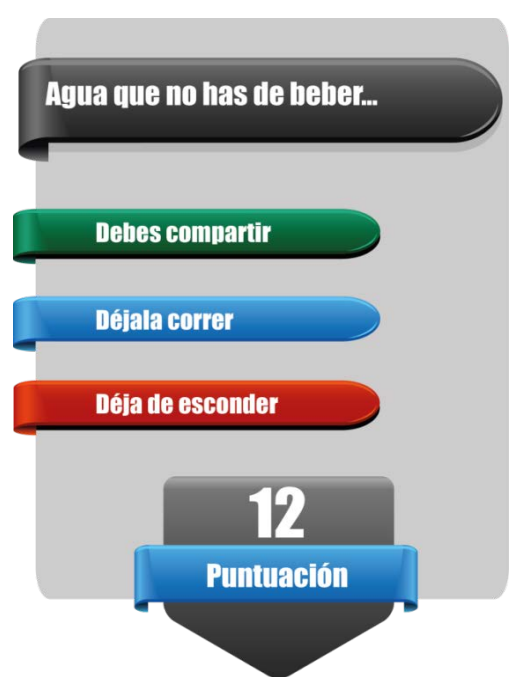

$\operatorname{Axiom(s):~}$

- Axiom 1. I feel I belong, but part of me is separated from the outside world.

- Axiom 3. My experience of the world is selective and has a purpose.

Possible emotions and reaction of the system:

Despair

Actions:

Present an easier exercise;

Given hints or clues to indicate the correct answer(s).

Frustration

Actions:

Have the patient select another option;

Give the correct sequence;

Change the activity.

EXERCISE 3

Stimulated area: Orientation and Memory;

Level of difficulty: Medium;

Periodicity: 2 - 3 times per week;

Instructions: Play the song and identify who sings it.

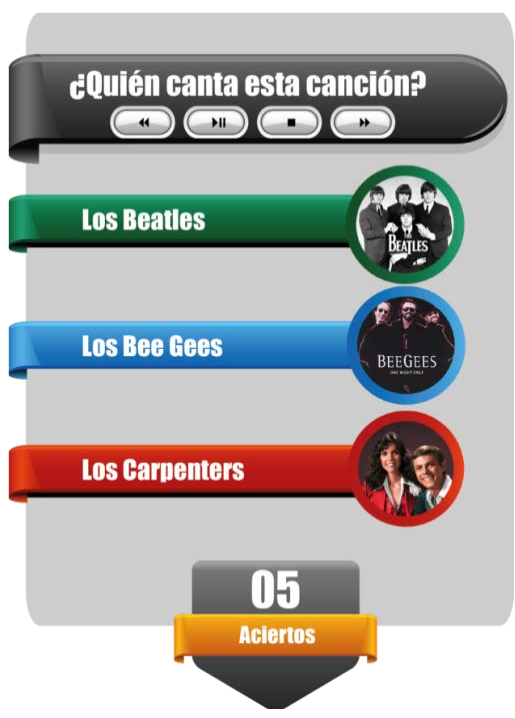


$\operatorname{Axiom}(\mathbf{s}):$

- Axiom 1. I feel I belong, but part of me is separated from the outside world.

- Axiom 2. I feel that my perception of the world is mixed with feelings of past experiences.

- Axiom 5. I have feelings, emotions and moods that determine what I will do.

Possible emotions and reaction of the system:

Despair

Actions:

Allow the song to play again;

Present an easier exercise;

Give hints or clues to indicate the correct answer(s).

Sadness

\section{Actions:}

Give the correct answer;

Change the activity.

\section{Conclusions}

The development of this work allows us to consider the emotions as a link with the phenomenon of the consciousness. In the case study, we consider this to be of utmost importance due to that the consciousness is the interface through which humans are able to contend with the environment and find purpose for their existence, and is what controls their activities.

In patients with $\mathrm{AD}$, there is significant deterioration of these capacities or functions, hence the importance to consider the emotions in the analysis and design phase of the reactive interface and in the case study, paired with the phenomenon of the consciousness, the latter being the experience that is affected in AD patients. This permits enhancement of the reactive interface, in making it more empathetic with the users.

This project finalizes the analysis and design stage, having developed the first prototype being tested by experts. The subsequent stages will work in refinement of the implementation, as well as in the application of a pilot run to test its performance and make the necessary adjustments for efficient, effective and satisfactory use. This proposal will serve as support in the application of cognitive stimulation in day centers for AD patients in the mild to moderate stage of the illness.

Mexico needs more hard information on a national level in order to further the knowledge of the actual current and future human, social and economic impact it represents for Mexico, and the burden that it, as an illness, generates.

According to Zuñiga [6], solely two of the evaluated cognitive functions - attention and judgment-showed statistically significant changes. It is important to point out that few studies exist that evaluate the effects of intervention with cognitive and physical stimulation programs, for the elderly with dementia, least of all in countries with middle- and low-income.

This last thought implies an awareness of the severity of the illness and the importance of economic investment in this type of application. Today we have the first prototype whose use can be seen in the next internet link, showing a video of their basic operation.

https://www.dropbox.com/sh/ob9qkvyrn3okck3/AAA7kVkxuuZ4J-r9nJ65ulpIa?dl=0

\section{Acknowledgements}

This project forms part of the research developed by Itzel Iraís Montiel-Bernal to obtain an engineer B.Sc. in Computer Systems Engineer from the Escuela Superior de Cómputo-IPN, and of Eric Allier-Pavia to obtain a specialty Diploma in Diseño, Visualización de la Información from Universidad Autónoma Metropolitana-Azcapotzalco, also it forms part of the research Project artificial consciousness and emotions from the same University.

\section{References}

[1] Figure 1. Plan de acción Alzheimer y otras demencias. México. 2014. (2014). México: Instituto Nacional de Geriatría/ Secretaría de Salud. Primera edición. http://www.geriatria.salud.gob.mx/descargas/noticias/plan alzheimer.pdf 
[2] Sosa-Ortiz, A.L., Acosta-Castillo, I. and Prince, M.J. (2012) Epidemiology of Dementia and Alzheimer's Disease. Archives of Medical Research, 43, 600-608. http://dx.doi.org/10.1016/j.arcmed.2012.11.003

[3] Prince, M., Brodathy, H., Uwakaew, R., Acosta, D., Ferri, C.P., Guerra, M., Huang, Y., Jacob, K.S., Llibre Rodríguez, J.J., Salas, A., Sosa, A.L., Williams, J.D., Jotheewsaran, A.T. and Liu, Z.R. (2012) Strain and Its Correlates among Caregivers of People with Dementia in Low-Income and Middle-Income Countries. A 10/66 Dementia Research Group Population-Based Survey. International Journal of Geriatric Psychiatry, 27, 670-682. http://dx.doi.org/10.1002/gps.2727

[4] García, N., Acosta, I. and Sosa, A.L. (2014). La Carga de los Cuidadores de Adultos Mayores con Demencia en una Región Rural. Psicología y Salud, 24, 35-43.

[5] Acosta-Castillo, I., Sosa-Ortiz, A.L., Borges, G. and Prince, M. (2011) Síntomas Neuropsiquiátricos en Adultos Mayores de Áreas de Mediano y Bajo Ingreso Económico. Grupo de Investigación en Demencia 10/66. Archivos de Neurociencias, 16, 18-23.

[6] Zúñiga, T., Trujillo, Z., Cortés, G., Acosta, I. and Sosa, A.L. (2014) Impacto de los Programas de Estimulación en Adultos Mayores con Demencia que Asisten a un Centro de Día. Archivos de neurociencias (México, D.F.), 19, 192198.

[7] Laureano-Cruces, A.L., Sosa-Ortiz, A.L., Mora-Torres, M., Rodríguez-García, A. and Ramírez-Rodríguez, J. (2012) La Consciencia como Interfaz entre el Mundo Interno y Externo. En Avances de las Mujeres en las Ciencias, las Humanidades y todas las disciplinas. Libro Cientifico, I, 246-258.

[8] Mora-Torres, M., Laureano-Cruces, A.L., Gamboa-Rodríguez, F., Ramírez-Rodríguez, J. and Sánchez-Guerrero, L. (2014) An Affective-Motivational Interface for a Pedagogical Agent. International Journal of Intelligence Science, 4 , 17-23. http://www.scirp.org/journal/ijis http://dx.doi.org/10.4236/ijis.2014.41003

[9] Lavazza, A. (2007) Sense as a "Translation" of Mental Contents in Artificial Consciousness. Edited by Antonio Chella and Ricardo Manzzoti, Academic Press, Waltham.

[10] Mora-Torres, M., Laureano-Cruces, A.L. and Velasco-Santos, P. (2011) Estructura de las Emociones dentro de un Proceso de Enseñanza -Aprendizaje. Revista Perfiles Educativos-UNAM, XXXIII, 64-79.

[11] Manrique-Espinoza, B., Salinas-Rodríguez, A., Moreno-Tamayo, K.M., Acosta-Castillo, G.I., Sosa-Ortiz, A.L., Gutiérrez-Robledo, L.M. and Téllez-Rojo, M.M. (2013) Condiciones de Salud y Estado funcional de los Adultos Mayores en México. Salud Pública México, 55, s323-s331.

[12] Dos Santos, L. and Torales, P.R. (2001) Enfermedad de Alzheimer-Parte I. Revista de Posgrado de la Cathedra VIa Medicina, 108, 6-11. http://med.unne.edu.ar/revista/revista108/alzheimer.html

[13] Mograbi, D.C., Ferri, C., Sosa, A.L., Stewart, R., Larks, J., Brown, R. and Morris, R.G. (2012) Unawareness of Memory Impairment in Dementia: A Population-Based Study. International Psychogeriatrics, 24, 931-939. http://dx.doi.org/10.1017/S1041610211002730

[14] Zúñiga, T., Sosa, A.L., Alonso, M.E. and Acosta, G.I. (2010) Dependencia y Maltrato en el Anciano con Demencia. Pers Bioet, 1, 56-66.

[15] Aleksander, I. (2005) The World in My Mind, My Mind in the World. IA Press, Iowa City.

[16] Van Eeresel, P. (2012) Mais alors qu'est que la consciente? Votre Cerveau N'a Pas De Fini De Vous Etonner. Edited by Clés Albin Michel.

[17] Picard, R. (1998) Affective Computing. MIT, Cambridge.

[18] Laureano-Cruces, A.L. and Hegmann-González, E. (2011) Maze: A Videogame That Adapts to the User's Emotions According to His Behavior. ICGST-Artificial Intelligence Machine Learning Journal, 11, 21-25. http://www.icgst.com/paper.aspx?pid=P1121102462

[19] Ortony, A., Clore, G.L. and Collins, A. (1996) La estructura cognitiva de las emociones. Siglo XXI, Madrid. 